\title{
The perception of time
}

\author{
LORRAINE G. ALLAN \\ McMaster University, Hamilton, Ontario L8S 4K1, Canada
}

\begin{abstract}
The present paper organizes and evaluates selected portions of the time perception literature. Emphasis is on data and theory concerned primarily with judgments of brief temporal intervals. Research concerning the psychophysical law for time, Weber's law, the time-order error, and the role of nontemporal information is evaluated. This is followed by a consideration of current, quantitatively oriented, theoretical formulations for time perception.
\end{abstract}

Five years ago, Allan and Kristofferson (1974a) could write: "There are few quantitative theories of duration discrimination and few established empirical phenomena to guide theorizing'" (p. 26). Since that time, there has been a dramatic change. Many articles on the discrimination of brief temporal intervals, and several new quantitative models, have appeared in a period of a few years. The last major general review and evaluation of the literature concerned primarily with the perception of brief temporal intervals was published almost 30 years ago by Woodrow (1951). Recent reviews by Doob (1971), Fraisse (1963), and Pöppel (1978) emphasize the perception of relatively long temporal intervals. The present paper organizes and evaluates those portions of the more recent time perception literature concerned primarily with judgments of brief temporal intervals, generally less than $10 \mathrm{sec}$, by normal human adults. First, the more common methods used are described. Second, the research relevant to four central issues is evaluated. Finally, current and quantitatively oriented theoretical formulations for time perception are considered.

Even within these limits, no attempt at covering all the relevant literature was made; the literature considered is best described as representative rather than comprehensive. (A fairly comprehensive recent bibliography of the time perception literature is Zelkind and Sprug, 1974.)

\section{METHODOLOGY}

Past attempts to impose order on the methodology of time perception (e.g., Bindra \& Waksberg, 1956; Clausen, 1950; Woodrow, 1951) usually agreed that there were four basic methods. In verbal estimation,

Preparation of this manuscript was supported by the Natural Sciences and Engineering Research Council of Canada. I would like to thank A. B. Kristofferson and Cem Kaner for reading and commenting upon an earlier draft, and Martha Teghtsoonian for her helpful editorial comments. Requests for reprints should be sent to Lorraine G. Allan, Department of Psychology, McMaster University, Hamilton, Ontario L8S 4K1, Canada. the experimenter $(\mathrm{E})$ presents a temporal interval and the subject (S) gives a verbal estimate of its duration in clock time. In production, $\mathrm{E}$ states the duration of the interval in clock time and $S$ produces that interval. In reproduction, $\mathrm{E}$ presents the temporal interval and $S$ reproduces it. In the method of comparison, E presents two temporal intervals in succession and $\mathrm{S}$ makes a judgment of relative duration.

Many studies asked (1) which method produced judgments of greatest accuracy (least difference from the presented temporal interval) and consistency (least intra- and intersubject variability), and (2) whether there were significant correlations among the basic methods (e.g., Carlson \& Feinberg, 1968a, 1968b, 1970; Danziger \& Du Preez, 1963; Doehring, 1961; Du Preez, 1963; Gilliland \& Humphreys, 1943; Gilliland \& Martin, 1940; Goldfarb \& Goldstone, 1963b; Goodfellow, 1934; Hawkes, Bailey, \& Warm, 1961; Hornstein \& Rotter, 1969; Kruup, 1961; McConchie \& Rutschmann, 1970, 1971; Ochberg, Pollack, \& Meyer, 1965; Siegman, 1962; Spivak \& Levine, 1964; Treisman, 1963). No single method can claim consistent superiority. Furthermore, what emerges clearly is a lack of correlation among the methods, which prompted Carlson and Feinberg (1970) to conclude that "present methods of assessing time judgment are of uncertain validity and generalizability" (p. 171).

Most early research on time perception was nontheoretical: The subject's responses were treated as direct estimates of perceived duration. Recently, several quantitative models have been generated, and new methods, dictated by the models, have become popular. Those frequently used are listed in Table 1 . There are two basic research methodologies, duration scaling and duration discrimination. In a duration scaling task, $\mathrm{S}$ is asked about the perceived durations of a set of easily discriminable temporal intervals; in a duration discrimination task, $\mathrm{S}$ is asked to distinguish among a set of highly confusable intervals.

\section{Duration Scaling}

A variant of the method of verbal estimation is 
Table 1

Methods Used in Time Perception Studies

Duration Scaling

(1) Verbal Estimation

(2) Magnitude Estimation

(3) Category Rating

(4) Production

(5) Ratio-Setting*

(6) Synchronization
Duration Discrimination

(1) Method of Comparison

(a) forced-choice with a fixed standard

(b) forced-choice with a roving standard

(2) Single Stimulus

(3) Many-to-Few

(4) Identification

${ }^{*}$ Reproduction, fractionation, multiplication.

that of magnitude estimation. Here the S's verbal response is not in temporal units. Rather, $\mathrm{S}$ assigns a number to represent the magnitude of the perceived duration. A standard duration may be presented on each trial, or just at the beginning of the session, or no standard may be designated. A similar scaling task is category-rating. E presents the temporal interval and $S$ locates its perceived duration in one of $\mathrm{m}$ ordered categories. In category rating, the boundaries and subdivisions of the response scale are defined by $\mathrm{E}$; in magnitude estimation, they are defined by $\mathrm{S}$.

Reproduction is a subcategory of the method of ratio-setting. In a ratio-setting task, $\mathrm{E}$ presents the temporal interval and $S$ generates a specified proportion of that interval. When the proportion is 1.00 , the task is referred to as reproduction; less than 1.00 , fractionation; greater than 1.00, multiplication.

A variant of the method of reproduction is synchronization. In one version, E presents a fixed duration standard and $S$ responds in synchrony with its termination. In another version, $E$ presents a series of brief events once per unit time and $S$ reproduces a sequence of responses at the same rate.

\section{Duration Discrimination}

In the method of comparison, two duration values are presented sequentially on each trial. Usually one value is constant within a block of trials and is referred to as the standard; the other value varies from trial to trial and is referred to as the comparison or the variable. In the forced-choice (FC) version of the method of comparison, the standard duration can occur either first or second and $S$ is required to indicate which. In the roving-standard version, the standard value also varies from trial to trial.

In the method of single stimulus (SS), one of two possible duration values is presented on each trial and $S$ indicates whether it was the shorter or the longer value. In the many-to-few modification, the number of possible stimulus values is increased but the binary response maintained. In the identification modification, both the number of possible stimulus values and of response alternatives is increased. Identification differs from category-rating in that the duration values are highly confusable.

\section{FOUR CENTRAL ISSUES}

The following four questions have been addressed by the various theoretical accounts of time perception: (1) What is the psychophysical law for time perception? (2) Does Weber's law hold for time perception? (3) What is the source of the time-order error? (4) What is the influence of nontemporal information on temporal judgments?

\section{The Psychophysical Law for Time Perception}

At first glance, there appears to be no consensus regarding the nature of the relationship between stimulus time and perceived time. Early studies (see Woodrow, 1951) often described the data in terms of Vierordt's law-that short intervals are overestimated and long ones underestimated. The indifference interval is that which is neither overestimated nor underestimated. Woodrow $(1930,1933$, 1934) demonstrated that there was no universal tendency for Vierordt's law to hold, and concluded that, even when an indifference interval was found, there was considerable variablility in the value across laboratories and that "even under fixed experimental conditions, there is no single indifference interval valid for all subjects" (Woodrow, 1951, p. 1226).

More recent studies have tried to determine the functional form of the relationship between stimulus time and perceived time. The terms perceived, internal, subjective, psychological, and apparent duration (time) are used interchangeably; generally speaking, they refer to the temporal value used by the subject in making his judgment. Efron (1970, 1973) has argued that duration of a percept is not necessarily the same as perceived duration. He concluded, based on simultaneity judgments, that for stimuli briefer than a critical duration (about $150 \mathrm{msec}$ ), perceptual offset latency increases as stimulus duration is decreased, the result being a constant minimum perceptual duration, while for stimuli longer than $150 \mathrm{msec}$ the duration of the percept increases linearly with stimulus duration. However, new data from simultaneity tasks similar to Efron's (Allan, 1976; Penner, 1975, 1978) do not confirm his basic finding. Penner (1975) suggested that, although 
there may be a constant minimum perceptual duration, her subjects adopted different criterion values than did Efron's. Later Allan (1976) and Penner (1978) argued that Efron's results could be attributed entirely to criterion changes, and concluded that a strong case for a constant minimum perceptual duration had not been made.

Support for a power relation and for a direct linear relation as the psychophysical law has been claimed. The main support for a power function has been derived from ratio-setting data and from magnitude and verbal estimation data. Björkman and Holmkvist (1960), Eisler (1975), and Ekman (Note 1; Ekman \& Frankenhauser, Note 2) developed models for the analysis of ratio-setting temporal data. These models provide discrepant estimates of the power function exponent. For example, the average exponent reported by Björkman and Holmkvist (1960), by Ekman and Frankenhaeuser (Note 2), and by Frankenhaueser (1960), is considerably larger than 1.00 , whereas the average exponent reported by Eisler (1975) is about .84. While the average exponent over many studies derived from Eisler's model is about .90 (Eisler, 1976), there is considerable betweensubject (Allan, 1978; Eisler, 1975) and betweenexperiment (Eisler, 1976) variability. Further, Allan (1978) has shown that the same exponent value is not derived from reproduction, half-setting, and double-setting data. While Eisler (1975) does report some high correlations among ratio-setting exponents, he found that the correlation between exponents estimated from reproduction data and from halfsetting data was only .14.

Allan (1978) and Blankenship and Anderson (1976) have pointed out that, even though the ratio-setting models for duration have two parameters, it is not possible to obtain estimates for both parameters from conventional ratio-setting data. The parameter of interest is the exponent of the power function. The other parameter represents the proportional relationship between the duration values generated by $S$ and presented by $E$. In the ratiosetting models, it is assumed that the experimenterdefined proportion $(P)$ and the value adopted by $S$ (p) are identical. Only if the relationship between $\mathbf{P}$ and $p$ is assumed, can an estimate of the exponent be obtained. The conclusion derived from ratiosetting data, that time perception is not veridical, is as valid as this assumption. Based on her review of ratio-setting models, Allan (1978) suggested that, given the current status of model development for ratio-setting temporal data, these data should not be the basis for any firm conclusion regarding the form of the psychophysical law in time perception.

A large number of studies have concluded that verbal and magnitude estimates are a power function of stimulus duration (e.g., Bobko, Thompson, \& Schiffman, 1977; Eisler, 1975, 1976; Jones \& MacLean, 1966; Künnapas, Hallsten, \& Söderberg, 1973;
Michon, 1967; Painton, Cullinan, \& Mencke, 1977; Steiner, 1968; Stevens \& Galanter, 1957; Stevens \& Greenbaum, 1966). In a number of these studies (Bobko et al., 1977; Jones \& MacLean, 1966; Stevens \& Galanter, 1957), the estimate of the power function exponent was very close to unity, but in none of the studies was there any attempt to compare the goodness-of-fit of the power function with that of a linear function. Kaner and Allan (Note 3) have made this comparison. They obtained magnitude estimation data from 11 well-practiced subjects for three ranges of duration values. All subjects generated estimates for stimulus durations between 20 and $300 \mathrm{msec}$ (short range) and for durations between 400 and $8,100 \mathrm{msec}$ (long range); 10 of the subjects generated estimates for durations between 20 and $8,100 \mathrm{msec}$ (full range).

Kaner and Allan estimated for each subject the exponent $\mathrm{n}$ of the power function by determining the slope $n$ of the best fitting linear function in log$\log$ coordinates. For 29 of the 32 functions, the exponent $n$ was less than 1.00 , with a median value of .767. Kaner and Allan also determined the best fitting linear function, and found that for 23 of the 32 cases the coefficient of determination, $r^{2}$, was larger for the linear function than for the $\log -\log$ linear function $(p<.05)$. That is, a simple linear function often fit the data better than a power function, even in cases where the size of the exponent appears to rule out the linear function. These results indicate that arguments against linear models for time based solely upon the size of the power function exponent should be regarded with caution.

Eisler (1975) and Michon (1967) found that their data, when plotted in log-log coordinates, appeared curved, and they fit their data with two linear, loglog segments. Michon allowed both the slope and the intercept of the two segments to be different, while Eisler allowed only the intercept and the location of the point of intersection, the breakpoint, to vary. Kaner and Allan also found that two linear, log-log segments provided a better description of their data than the simple linear function. However, since the linear function accounted for most of the variance (mean $r^{2}=.99$ ), the improvement was negligible, especially since the two linear, log-log segments allowed for five parameters (two intercepts, two exponents, and one breakpoint value), whereas the linear function allows for only two parameters. Also, there was no between-subject consistency in the value of the breakpoint, or any sensible relationship among the breakpoint values for the different ranges. Furthermore, it should be noted that a satisfactory theoretical rationale for a breakpoint analysis is not available.

In all published verbal and magnitude estimation studies of time, the empirical relationship between the subject's estimates and stimulus duration has 
been interpreted as a direct reflection of the psychophysical law. It has been assumed, implicitly or explicitly, that the obtained function represents the transformation of stimulus time to perceived time, and that the subject's response is a simple linear transformation of perceived time. This assumption has been questioned. For example, Ekman (1964) pointed out that if the internal representations of the response value and of the stimulus value were both logarithmically related to the external values, the power law would result.

Moreover, it has been shown that for other stimulus dimensions, responses are not necessarily a simple linear transformation of the internal stimulus values. The extensive work of Curtis and of Rule (e.g., Curtis, 1970; Curtis, Attneave, \& Harrington, 1968; Rule, Curtis, \& Markley, 1970) has shown that magnitude estimation data can be analyzed in terms of at least two stages: an input stage that transforms stimulus values to perceived values and an output stage that transforms perceived values to responses. Recent work on magnitude estimation of loudness (e.g., Braida \& Durlach, 1972; Durlach \& Braida, 1969; Green \& Luce, 1974; Green, Luce, \& Duncan, 1977; Jesteadt, Luce, \& Green, 1977; Luce \& Green, 1974) also points to the necessity of a more detailed analysis of magnitude estimation data. None of these approaches have been applied to magnitude estimation of temporal intervals.

However, a beginning in this direction has been made with category-rating data. Curtis and Rule (1977) applied their two stage model to category ratings of temporal intervals ranging from about .5 to $10 \mathrm{sec}$, and Blankenship and Anderson (1976) made use of the functional measurement approach (Anderson, 1977) with temporal intervals ranging from 0 to $30 \mathrm{sec}$. The data from both studies are consistent with a linear relationship between perceived duration and stimulus duration.

The duration discrimination data also provide support for a linear relationship. A number of decision theory models specify that the expected value of the internal duration distribution is a linear function of stimulus duration (Allan, Kristofferson, \& Wiens, 1971; Creelman, 1962; Kinchla, 1972). A large quantity of data has been analyzed in terms of these models, and in general the data are in accord with the linearity assumption. Furthermore, Kristofferson (1977) has shown that, under some circumstances, duration discrimination data are compatible with the real-time criterion model which states that, for the purpose of duration discrimination, there is no transformation of stimulus time into psychological time. According to this model, internal time is real time.

In summary, an adequate model for the analysis of ratio-setting temporal data has not yet been developed. The exponent derived from magnitude estimation data is frequently close to unity, and Kaner and Allan (Note 3) have demonstrated that even when the exponent deviates considerably from 1.00 , a two-parameter linear function often provides a better description of the data than a two-parameter power function. Category-rating and discrimination data are consistent with a linear relationship between perceived time and stimulus time.

\section{Weber's Law}

According to Weber's law, the just noticeable diference, $\Delta$, between two stimulus durations is a constant proportion, $\mathrm{k}$, of $\mathrm{d}_{0}$, the shorter of the two values. In a discrimination task, the value of $\Delta$ can be estimated from the slope of the psychometric function, and one statistic that has been used is the standard deviation, SD(d). Thus, if Weber's law holds, the standard deviation of the distribution of temporal intervals generated in a scaling task should be directly proportional to the mean duration value being generated.

Allan and Kristofferson (1974a) and Woodrow (1951), who reviewed the relevant literature, concluded that there was little support for this simple version of Weber's law. In scaling studies, the standard deviation of the generated response distribution increases monotonically with but not proportionally to the mean response value (e.g., Doehring, 1961; Woodrow, 1930, 1933). In discrimination studies, the just noticeable difference is an increasing function of $\mathrm{d}_{0}$, but the relationship is not usually linear (e.g., Abel, 1972a, 1972b; Blakely, 1933; Creelman, 1962; Henry, 1948; Kinchla, 1972; Small \& Campbell, 1962; Stott, 1933; Tanner, Patton, \& Atkinson, 1965).

Allan and Kristofferson (1974a) summarized data from their laboratories which indicated that, for wellpracticed subjects, $\Delta$ remained invariant over a wide range of $d_{0}$ values (Allan \& Kristofferson, 1974b; Allan et al., 1971; Rousseau \& Kristofferson, 1973; Kristofferson, Note 4). More recently, Hopkins (Note 5) and Kristofferson (1976) have reported synchronization data which show that the variability of the generated response distributions is constant for synchronization intervals from about 200 to $550 \mathrm{msec}$. Thomas and Brown (1974) have reported reproduction data that also indicate constancy in the standard deviation of the response distributions: While the average standard deviation of reproduced intervals was larger for a stimulus range of $4,500-5,500 \mathrm{msec}$ than for one of 750-1,750 msec, there was no systematic relationship between the average standard deviation and stimulus value within either range.

Probably the data most often cited in favor of Weber's law are those of Treisman (1963), generated using the methods of estimation, production, repro- 
duction, single stimuli, and comparison. However, Treisman concluded that his data did not support proportionality, though they could be described by $\mathrm{SD}(\mathrm{d})=\mathrm{k}(\mathrm{d}+\mathrm{a})$.

Four recent studies (Divenyi \& Danner, 1977; Getty, 1975, 1976; Thompson, Schiffman, \& Bobko, 1976) have provided data that have been interpreted as supportive of Weber's law. Thompson et al. (1976) determined the Weber fraction for three duration ranges. They found the Weber fraction to be $.056, .053$, and .043 for stimulus duration ranges centered at 1,2 , and $3 \mathrm{sec}$, respectively, although an analysis of variance on the individual subject Weber fractions indicated a nonsignificant effect due to duration.

If Weber's law holds, the function relating log $\Delta$ to $\log \mathrm{d}_{0}$ should have unit slope. Divenyi and Danner (1977) obtained a slope of .93 for data averaged over three subjects, and concluded that their data supported the view that Weber's law holds for time perception. However, their function is based on only three values of $d_{0}$.

The data that most strongly support Weber's law are those of Getty $(1975,1976)$. He argued that variability in a discrimination task arises from several sources, only some of which are dependent on stimulus magnitude. If the variance of the observed psychometric function is partitioned into two components,

$$
\operatorname{Var}(d)=k^{2} d^{2}+V_{R} \text {, }
$$

where $V_{R}$ represents the stimulus-independent variance, taking the square root of Equation 1 results in what Getty refers to as a generalized form of Weber's law,

$$
\operatorname{SD}(d)=\left(k^{2} d^{2}+V_{R}\right)^{1 / 2}
$$

Data from two well-practiced subjects were in excellent agreement with Equation 2 for duration values between 50 and 2,000 msec (Getty, 1975), and data from a synchronization task were in better agreement with Equation 2 than with a model that specifies a proportional relation between the variance of the produced intervals and stimulus duration (Getty, 1976).

In summary, the conclusion reached by Allan and Kristofferson (1974a) and by Woodrow (1951) is still justified: Weber's law in its simple form does not hold for time perception. Getty's generalized form of Weber's law has received strong support, and it would be of value to reanalyze existing data in terms of Equation 2. However, the data reported by Allan (Allan \& Kristofferson, 1974b; Allan et al., 1971), by Hopkins (Note 5), by Kristofferson (Note 4, 1976; Rousseau \& Kristofferson, 1973), and by Thomas and Brown (1974) could not be described by Equation 2. Clearly, a viable theory for time perception will have to account both for data that demonstrate invariance and for data that are consistent with Getty's generalized form of Weber's law.

\section{The Time-Order Error in Temporal Judgments}

In scaling and discrimination tasks involving the sequentfal presentation of two or more duration values, it has frequently been reported that the order of presentation influences performance. Most of the systematic work on presentation order effects has used the method of comparison, in particular the forced-choice (FC) procedure (e.g., Blakely, 1933; Philip, 1947; Stott, 1933, 1935; Woodrow, 1935; Woodrow \& Stott, 1936). In a typical FC task, there are two orders of presentation: either the shorter duration follows the longer by $t$ msec $\left(S_{1} S_{0}\right)$ or the longer follows the shorter $\left(S_{0} S_{1}\right)$. Correct judgments can be summarized by two conditional probabilities, $P\left(R_{10} \mid S_{1} S_{0}\right)$ and $P\left(R_{01} \mid S_{0} S_{1}\right)$, where $R_{10}$ indicates a judgment that the longer duration was presented first, $R_{01}$ the reverse. The signed difference between the two conditional probabilities, $\mathbf{P}\left(\mathbf{R}_{10} \mid \mathbf{S}_{1} \mathbf{S}_{0}\right)-\mathbf{P}\left(\mathbf{R}_{01} \mid \mathbf{S}_{0} \mathbf{S}_{1}\right)$, is called the time-order error (TOE). Early studies found that the TOE was duration-dependent. For brief durations, TOE was often positive; for longer durations, it was often negative. The duration that resulted in zero TOE was referred to as the indifference interval.

The basic interpretation of TOE offered by Woodrow (1935) was that the perceptual duration of the first-presented duration "gravitated" towards a remote standard, the indifference interval. The greater the discrepancy between the presented stimulus duration and the indifference interval, the greater the gravitational effect. This explanation places the source of TOE in perceptual memory.

Stott $(1933,1935)$, Woodrow (1935), and Woodrow and Stott (1936) found that a negative TOE became less negative and a positive TOE became less positive with practice in a comparative judgment task involving a number of variable durations. They suggested that assimilation of the perceived duration of the firstpresented duration to the average value of all the duration values attenuates TOE with practice.

Allan and Kristofferson (1974a) summarized the data from more recent studies involving comparative judgments of brief stimulus durations (Allan, Kristofferson, \& Rice, 1974; Carbotte, 1973; Creelman, 1962; Small \& Campbell, 1962). For a constant set of duration values, for some subjects no TOE was observed, for some it was positive, and for others negative. Such results suggested that the source of TOE might be in the decision process rather than in perceptual memory. However, the investigation of TOE was not the major purpose of these studies, 
and it has since been demonstrated that use of trial feedback could have influenced the subject's responding in such a way as to attenuate or even eliminate any systematic relationship between the size and sign of TOE and the stimulus duration values being compared (Jamieson \& Petrusic, 1976, 1978).

A number of studies designed specifically to investigate TOE in duration discrimination tasks have recently been reported (Allan, 1977; Hellström, 1977; Jamieson, 1977; Jamieson \& Petrusic, 1975a, 1975b, 1975c, 1976, 1978). Hellström (1977) and Jamieson and Petrusic $(1975 \mathrm{a}, 1975 \mathrm{~b}, 1976,1978)$ argued that, if the source of TOE was response bias, TOE should be dependent on the particular mode of responding, whereas if TOE was a perceptual or memory phenomenon, it should be independent of response instructions. Hellström (1977) ran four groups of subjects: The 1LS group was instructed to make a longer/shorter decision about the first duration presented and the 2LS group about the second duration presented; the L12 group had to decide which duration (first or second) was longer, and the S12 group which duration was shorter. Hellström considered a decision theory model which represented the subject as comparing the two internal duration values by computing a duration difference value which was then compared to values of a difference criterion. He correctly argued that if TOE was simply a matter of response bias or preference (longer vs. shorter or first vs. second), then the various instructions should yield different response patterns and therefore differential TOE results. For example, if the subject has a preference for making a longer response over a shorter response, then under the $1 \mathrm{LS}$ condition this would lead to more correct responses to $S_{1} S_{0}$ than to $S_{0} S_{1}$ and a positive TOE, while under the $2 \mathrm{LS}$ condition it would lead to more correct responses to $S_{0} S_{1}$ than to $S_{1} S_{0}$ and a negative TOE. Hellström used two duration ranges, one centered at $1 \mathrm{sec}$, the other at $2 \mathrm{sec}$, within the same experimental session. He found a positive TOE for $1 \mathrm{sec}$ and a negative TOE for $2 \mathrm{sec}$ for all four groups of subjects, and concluded that his data ruled out the decision process as the source of TOE.

Hellström's (1977) conclusion is not justified if the decision process is conceptualized in a slightly different manner. For example, suppose the subject sets a criterion difference value and labels as long-short $\left(R_{10}\right)$ all differences larger than, and as short-long $\left(R_{01}\right)$ all differences smaller than, the criterion value. $R_{10}$ is translated to longer by the $1 \mathrm{LS}$ group, to shorter by the $2 \mathrm{LS}$ group, to first by the L12 group, and to second by the $\mathrm{S} 12$ group. There is no reason to suppose that the different instructions would influence the placement of the criterion. Hellström's data are incompatible with the particular decision process that he describes, but not necessarily with any decision process. A similar counterargument can be made for the instruction data reported by Jamieson and Petrusic (1975a, 1975b, 1976, 1978).

Other arguments against a decision process source of TOE have also been advanced. Jamieson and Petrusic (1975a) note that, in the absence of trial feedback, TOE occurs in the predicted direction for individual subjects, and argue that such betweensubject consistency implies the unlikely event that all subjects adopt a similar response bias or criterion. As a counterexample, Allan (1977) suggested a model that places the source of TOE in the decision process and predicts that TOE should be positive for short durations and negative for long.

In her experiment, Allan used a roving-standard design. Jamieson (1977) has argued that data from a roving-standard design reflect primarily assimilation effects rather than TOEs. In assimilation, the memory of the first duration is influenced by the average duration value presented, so that durations longer than the average decrease in magnitude while held in memory and durations briefer increase. Jamieson reanalyzed Allan's data in terms of three versions of Luce and Galanter's (1963) basic choice model. To allow for presentation-order effects in the form of TOEs to occur, Luce and Galanter suggested that a parameter representing a multiplicative bias be associated with the second-presented stimulus. Jamieson developed an assimilation version of the choice model by introducing a parameter to represent the memory distortion of the first-presented stimulus. The third version of the choice model contained both the TOE and assimilation parameters. All three versions provided a better account of Allan's rovingstandard data than did the model that she suggested.

Jamieson (1977) concluded that there were at least two presentation order effects, TOE and assimilation. What is puzzling about his reanalysis of Allan's (1977) data is that while he (Jamieson \& Petrusic, $1975 \mathrm{a}, 1975 \mathrm{~b}, 1976,1978$ ) has consistently argued that TOE is not a decision criterion or response bias phenomenon, by using the Luce and Galanter bias version of the choice model, he treated TOE as a response bias phenomenon. Furthermore, if TOE is neither assimilation nor bias, what is it?

In retrospect, it could be argued that the approach taken in recent research on TOE is counter-productive. An argument over whether the source of TOE is in perceptual memory or in the decision process, outside the framework of a general theory, is likely to generate many data but few firm conclusions. Jamieson and Petrusic (1975a, 1975b, 1975c, 1976, 1978) have not provided a theoretical account for their provocative data. Hellström's (1977) adaptation/ weighting model is by far the most systematic theoretical account of TOE. Each of the two internal duration values generated on a trial is modified by 
the adaptation level or mean subjective duration, and differential weights are then applied to the modified internal values. The response is based on a comparison of these weighted internal values with a criterion internal value. The model predicts that the sign and magnitude of TOE should be dependent upon the duration values being compared, and Hellström presents various versions of the model which, in general, provide a good description of his data. Further, Hellström (Note 6) identifies the differential weights associated with the first and second duration stimuli with retroactive and proactive interference effects, respectively. His interpretation of the weight parameters is consistent with the findings of Jamieson and Petrusic $(1975 a, 1975 b, 1976,1978)$ that TOE, whether positive or negative, tends toward zero as the interduration interval, $t$, is increased. Interference effects should decrease with increasing $t$, and therefore so should TOE.

At its present stage of development, Hellström's model is directed towards providing an account of TOE and does not address other aspects of performance in time perception tasks. The only general theory for time perception that incorporates TOE is Eisler's (1975). As Eisler himself notes, his TOE expression has many degrees of freedom. More important, an evaluation of the TOE aspect of Eisler's model has not been reported. Future research should place greater emphasis on incorporating TOE into general theories of time perception.

\section{The Role of Nontemporal Information}

It is well documented that intervals having identical stimulus durations are not always judged as equal in perceived duration. Rather, the judgment is influenced by such nontemporal characteristics of the marker as its modality, nature (filled vs. empty), energy, and complexity. In this section, the effect of these variables on the judgment of temporal intervals presented in the visual and auditory modalities will be considered.

Goldstone and Goldfarb (Goldfarb \& Goldstone, 1964; Goldstone, 1968; Goldstone, Boardman, \& Lhamon, 1959; Goldstone \& Goldfarb, 1963, 1964a, 1964b; Goldstone, Jernigan, Lhamon, \& Boardman, 1959; Goldstone \& Lhamon, 1974) have reported data showing that a filled auditory interval is judged longer than a filled visual interval of the same stimulus duration. This modality difference has been demonstrated using a number of different tasks, over a wide range of duration values, for filled visual intervals of various intensities and wave lengths, and for filled auditory intervals of various intensities and frequencies. Other investigators have also reported that a filled auditory interval appears longer than a filled visual interval (e.g., Behar \& Bevan, 1961; Stevens \& Greenbaum, 1966). However, conflicting data do exist. Tanner et al. (1965) report that for duration values around $.5 \mathrm{sec}$ a visual filled interval was judged as longer than an auditory filled interval, and that for longer durations judged duration was not affected by modality. Hawkes et al. (1961), Bobko et al. (1977), and Brown and Hitchcock (1965) did not find a modality effect.

A filled interval is judged as longer than an empty interval of the same stimulus duration, the filled duration illusion (Craig, 1973; Goldfarb \& Goldstone, 1963a; Goldstone \& Goldfarb, 1963; Steiner, 1968), and an empty interval containing intervening discrete elements is judged as longer than a completely empty interval, judged duration increasing with the number of intervening elements (Adams, 1977; Buffardi, 1971; Israeli, 1930; Jones \& MacLean, 1966; Schiffman \& Bobko, 1977; Thomas \& Brown, 1974). Brown and Hitchcock (1965) found that visual filled intervals alternating between two intensities, and auditory filled intervals alternating between two intensities and frequencies, were judged as longer than constant filled intervals.

Other features of the signal marking the temporal interval have been shown to influence judged duration. It has usually been found that judged duration is directly related to the energy level of the filled interval (Berglund, Berglund, Ekman, \& Frankenhaeuser, 1969; Goldstone \& Lhamon, 1974; Goldstone, Lhamon, \& Sechzer, 1978; Steiner, 1968; Zelkind, 1973); however, Treisman (1963) reports a decrease in produced and reproduced intervals with increasing tone intensity. Woodrow (1928) showed that the duration of the marker of an empty interval influenced its perceived duration: Lengthening either the onset marker or the offset marker results in an increase in judged duration, with the duration of the onset marker having the larger effect. Schiffman and Bobko (1974) found that the more ordered and simple the flash pattern of eight lights marking a temporal interval, the shorter the reproduced duration. Thomas and Cantor $(1975,1976)$ found that judged duration was directly related to visual area of circles marking temporal duration. In a later study, Cantor and Thomas (1977) found that judged duration was directly related to the area of a visual form and inversely related to the perimeter.

"Cognitive" variables have also been shown to influence judged duration. Thomas and Weaver (1975) found that a brief tachistoscopic presentation of a word or of a "nonsense" word is judged as longer than the presentation of a blank field. Avant and Lyman (1975) and Avant, Lyman, and Antes (1975) report that the brief presentation of a three-letter nonword was judged as longer than that of a threeletter word, which in turn was judged as longer than that of a single letter. That is, the more "familiar" the stimulus, the shorter the judged duration. Devane 
(1974), Warm, Greenberg, and Dube (1964), and Warm and McCray (1969), also found an effect of stimulus familiarity on judged duration. However, their data indicate that judged exposure time for familiar words was longer than that of unfamiliar words.

Clearly, judged duration is very much influenced by the way in which the temporal interval is defined or marked. This might suggest that in a duration discrimination task the subject bases his judgment on some aspect of the presented interval other than its temporal extent. Allan and Kristofferson (1974a) reviewed a large number of duration discrimination studies over a wide range of duration values. They concluded that, for filled visual or auditory intervals, discrimination performance was independent of the intensity, frequency, or bandwidth characteristics of the signal as long as the signal was readily detectable (Abel, 1972a; Allan et al., 1971; Creelman, 1962; Henry, 1948; Small \& Campbell, 1962). Similarly, discrimination of empty intervals was independent of the temporal or intensity values of the visual or auditory signals that bound the interval to be judged (Abel, 1970; Carbotte \& Kristofferson, 1973; Nilsson, 1969, 1979; Rousseau \& Kristofferson, 1973). The only possible exception were Abel's (1972b) data, which indicated better discrimination of empty auditory intervals as the intensity of the noise markers was increased.

Recent data from discrimination studies of empty auditory intervals support the conclusions of Allan and Kristofferson (1974a). Divenyi and Danner (1977) conclude that for empty auditory intervals longer than $80 \mathrm{msec}$ "temporal discrimination performance was little affected even by large changes in the acoustic properties of markers" (p. 139). Penner (1976) found that discrimination performance for empty auditory intervals deteriorated only when the temporal and intensity values of noise markers were chosen randomly and independently for onset and offset from trial to trial, compared to a control condition of fixed intensity and duration markers.

It is somewhat surprising that there are no systematic comparisons of the discriminability of filled vs. empty intervals, or of visual vs. auditory signals. The little evidence that does exist suggests that discriminability may be affected. Abel (1972a, 1972b) found the discrimination of filled auditory intervals to be better than that of empty ones. Tanner et al. (1965) used a FC task and found superior discriminability of filled intervals for auditory than for visual signals. Accuracy was worst when one filled intervals was auditory and the other visual. Goodfellow (1934) reports that the auditory is less than the visual difference threshold. The research of Allan and of Kristofferson (Allan et al., 1971, 1974; Allan \& Kristofferson, 1974a, 1974b; Carbotte \& Kristofferson,
1973; Kristofferson, 1977; Kristofferson \& Allan, 1973; Rousseau \& Kristofferson, 1973; Kristofferson, Note 4) makes use of filled and empty visual and auditory intervals. These experiments show that discriminability is not constant across the various types of intervals. Thus, while discriminability of filled and unfilled intervals is independent of the energy values of the signals, discriminability appears to be dependent upon modality and upon whether the interval is filled or empty. A clearer picture of this dependency is needed.

In summary, there is an abundance of data on the role of nontemporal information in the perception of time, and a fairly clear empirical picture emerges. However, little effort has been directed at explaining the data and research directed at providing a theoretical base for the empirical relationships is needed. Of particular importance would be studies designed to determine why certain variations in the marker have a dramatic effect on scaling performance but leave discrimination performance unaffected.

\section{MODELS FOR TIME PERCEPTION}

Only those quantitative models concerned primarily with the perception of brief temporal intervals are considered in this section. The interesting and influential theorizing of investigators concerned mainly with relatively long temporal intervals (e.g., Doob, 1971; Fraisse, 1963; Michon, 1972, 1978; Ornstein, 1969) and models which are concerned with one particular issue (e.g., Björkman \& Holmkvist, 1960; Hellström, 1977; Ekman \& Frankenhaeuser, Note 2) are not discussed.

The models to be considered assume, implicitly or explicitly, that a common mechanism underlies time perception in the visual and auditory modalities. This assumption is supported by a number of empirical findings. Loeb, Behar, and Warm (1966) found that intermodal correlations of category-ratings of durations were of about the same magnitude as intramodal correlations. Warm, Stutz, and Vassolo (1975) demonstrated transfer effects in the reproductions of temporal intervals between the two modalities. Eijkman and Vendrik (1965) showed that detection of an increment in the duration of visual and auditory signals is completely correlated, and argued that this correlation indicates the existence of a common "duration" center.

Creelman (1962) developed the first quantitative model for duration discrimination, and a number of the more recent models derive from his counting model. These models are primarily concerned with the psychophysical law and with Weber's law. In the Creelman model, the subject bases his judgment on the number of pulses that are accumulated during a 
temporal interval. The source of these pulses consists of a large number of independent elements, each with a fixed probability of firing at any moment. The expected number of pulses accumulated during a d-msec interval and the variance in the number of accumulated pulses are both equal to $\lambda d$, where $\lambda$ is a constant representing the rate of firing of the pulse source. The distribution of the number of accumulated pulses is Poisson, but for large $\lambda d$ this distribution is approximately normal.

Most data analyzed in terms of the Creelman model have found that $\lambda$ is not constant across the d values used (e.g., Abel, 1972a, 1972b; Allan et al., 1971). These data have resulted in modifications of the basic Creelman model. For example, Divenyi and Danner (1977) explored the possibility that $\lambda$ was related to $\mathrm{d}$ by a negative exponential function. ${ }^{1}$ The expansion of Creelman's one rate parameter, $\lambda$, to three parameters plus the inclusion of an additional parameter results in a four-parameter model. Divenyi and Danner found that their model provided a reasonable description of their data. However, observed performance was consistently superior to predicted.

Kinchla (1972) proposed a model similar to Creelman's in predicting that the variance in the number of accumulated pulses was proportional to stimulus duration, but different in that the expected number of pulses was not equal to the variance but to stimulus duration. Kinchla did not propose a process which would generate these relationships. Also, the fit between the theory and her data is not particularly good.

Getty $(1975,1976)$ questioned the linear relationship between variance and stimulus duration predicted by the Creelman model and proposed, as an alternative, his Weber's law model, for which he presents strong supporting data. According to Getty, the standard deviation of the psychometric density function obeys Weber's law. There are two classes of modelslogarithmic and proportionality-which are consistent with this relationship, and he did not choose between them. Logarithmic models assume that stimulus duration is transformed logarithmically into internal duration, resulting in an internal distribution with a constant standard deviation and an expected value that increases logarithmically with stimulus duration. The human time-perception literature provides no support for a logarithmic psychophysical law. For example, Kaner and Allan (Note 3) found that in only 1 of 32 cases did a logarithmic function between magnitude estimates and stimulus duration provide a better fit to the data than either a power function or a linear function. Proportionality models assume that both the expected value and the standard deviation are proportional to stimulus duration. In this case, Weber's law applies to the stan- dard deviation of the internal distribution. A specific model that predicts proportionality between the standard deviation of the internal distribution and stimulus duration is Gibbon's (1977) scalar expectancy theory, which has had considerable success in the animal time literature. However, Gibbon's model is difficult to apply to the human duration discrimination task, since its underlying process is reinforcementdependent.

Allan and Kristofferson (1974a) summarized duration discrimination data from their laboratories, indicating a linear relationship between the expected value of the internal duration distribution and stimulus duration, and a standard deviation invariant over a considerable range of duration values. According to the onset-offset model proposed by Allan et al. (1971), all the variability in the internal duration values generated by a fixed stimulus duration is the result of variation in the time, with respect to stimulus time, at which the internal duration begins and ends. For any stimulus duration, $d$, the perceptual onset and offset latencies are each uniformly and independently distributed over a range of " q msec, resulting in a triangular distribution of internal durations spanning $2 \mathrm{q} \mathrm{msec}$, with an expected value proportional to stimulus duration and a variance, $q^{2} / 6$, independent of stimulus duration.

The onset-offset model specifies that the variability in the onset and offset perceptual latencies is independent of stimulus duration, and this independence appears to be true over a considerable range of stimulus durations. However, the variability does change between stimulus ranges (Allan \& Kristofferson, 1974b; Kristofferson, Note 4). This implies that the variability in the onset latencies is a function of stimulus duration, an unlikely possibility. Allan and Kristofferson (1974a) suggested, as an alternative, that the variability represented by the triangular distribution is part of the criterion mechanism, and Kristofferson (1977) has developed this alternative as the real-time criterion model. He showed that under some circumstances duration discrimination can be interpreted as temporal order discrimination. According to the model, the internal onset of the duration stimulus triggers an internally timed interval, the criterion. If the criterion interval ends before the internal offset of the duration stimulus, the subject responds long; if the duration stimulus ends before the criterion interval, the subject responds short. According to this model, errors in duration discrimination are due entirely to variability in the criterion, and the variance of the triangular distribution of criterion values depends upon the range and the values of the stimulus durations used in the discrimination task. Thus, for the data summarized by Allan and Kristofferson (1974a), a range of stimulus duration values appears to have the same 
variance merely because the variance arises from the internal criterion interval, a source which is the same for all the values. Although the real-time criterion model has not been extensively tested, it does provide an excellent fit to the data reported by Kristofferson (1977).

The models discussed above were developed to account for data from discrimination tasks and are concerned primarily with the psychophysical law and with Weber's law. At about the same time that Creelman (1962) proposed his counting model for duration discrimination, Treisman (1963) introduced a general theory for time perception. His internal clock model was proposed to account for both scaling and discrimination data. According to the model, a pacemaker produces a regular sequence of pulses at a constant rate which can be affected by the arousal level of the subject. These pulses are counted and are either read into the "store" for later retrieval by the comparator or directly entered into the comparator. The postulated characteristics of the pacemaker, the counter, the store, and the comparator yield predictions about Weber's law, the indifference interval, and other findings in the timeperception literature. Although the Treisman paper is frequently cited, there are no models which derive from it and little if any data have been analyzed in terms of it.

Eisler (1975) has proposed a general model for time perception which was developed to account for ratio-setting, magnitude estimation, and discrimination data. The model is based on the power law as the psychophysical law. The comparison on each trial is based on the simultaneous monitoring or parallel processing of two internal duration values-the internal value of the total duration (standard duration plus variable duration) and the internal value of the variable duration. The internal standard duration, which is the difference between the internal value of the total duration and the internal value of the variable duration, is continuously calculated and compared to the internal value of the variable. The overt response is based on this comparison. Eisler argues that the subject always makes a comparative judgment, even when only one stimulus duration is presented on a trial. In the SS task, it is assumed that the stimulus value on trial $n$ is compared with the stimulus value on trial $n-1$.

Eisler has not yet applied his model to discrimination data. We have already noted one difficulty with Eisler's model in its application to ratio-setting data. In order to apply the model, it is necessary to assume either a value for the exponent of the power function or that the subject's ratio is identical to the experimenter's ratio. When the model is applied to magnitude estimation data and category-rating data, the work of Curtis and Rule (1977) emphasizes the need for both an input and an output function. The Eisler model does not contain an output function. Furthermore, Curtis and Rule (1977) found that performance in a category-rating task involving the simultaneous presentation of two temporal intervals was very different from performance when the two intervals were presented sequentially. According to the Eisler model, the monitoring is supposed to be simultaneous even when the intervals are presented sequentially, and therefore it is difficult to reconcile the Curtis and Rule data with this aspect of the Eisler model.

Thomas and Brown (1974) have presented a general framework that provides a schema for the interrelation of data from different time perception tasks. Stimulus input is encoded as a vector, one component being an encoded, and the other the decoded, duration. They show that if the encoding function is of a particular form, and if decoding is the inverse of encoding, then a number of specific predictions about $\mathrm{d}^{\prime}$ in the SS task can be made. In particular, $d^{\prime}$ will be (1) directly related to the absolute difference between presented and reproduced intervals in a reproduction task, (2) inversely related to the variability of the reproduced intervals, and (3) unrelated to the slope of the curve relating reproduced and presented intervals. They also show that a reversible encoding function predicts average reproduced intervals that are linear with clock time, accounts for the overestimation of short intervals and the underestimation of long ones, and accounts for the filled duration illusion. As they note, the appropriate data for testing many of the predictions concerning the interrelation among various time-perception tasks do not exist.

In later papers, Cantor and Thomas (1977), Thomas and Cantor $(1975,1976,1978)$ and Thomas and Weaver (1975) have examined the role of nontemporal information in the processing of temporal information. Thomas and Weaver (1975) suggested that perceived duration was influenced by the time spent processing nontemporal information. Their model assumes that a stimulus of duration d, consisting of nontemporal information, $\mathrm{I}$, is analyzed by a timer and by an information processor. The output of the timer is a temporal encoding which is directly related to the stimulus duration, $d$; the output of the processor contains encodings of the nontemporal stimulus features and an encoding or memory of the time spent processing I. Attention is shared between the timer and the processor, and the values and the reliability of the two outputs are a function of the amount of directed attention. Perceived duration is a weighted average of the output of the timer and the encoding of the time spent processing I. Thus far, the application of the model has been restricted to $\mathrm{d}<100 \mathrm{msec}$. 
Thomas and Weaver (1975) demonstrated that manipulations to increase the time spent processing I and to increase the amount of attention devoted to the outcome of the processor led to an increase in the perceived duration of a fixed-value stimulus duration. Cantor and Thomas (1977) and Thomas and Cantor $(1975,1976)$ have presented data relating judgments of perceived duration and perceived size which are in accord with the Thomas and Weaver proposal that perceived duration is related to the time spent processing the nontemporal features of the stimulus.

Gomez and Robertson (1979) report that the size of the visual stimulus did not influence perceived duration when size was a between- rather than a within-subject variable. They appear to think that this result is incompatible with the model described by Thomas and Weaver (1975). However, it is not. The model specifies that perceived duration is influenced by the time spent processing nontemporal information if attention is directed to the information processor. When the task does not require the subject to process size information, it is entirely plausible that no attention is directed at the information processor and, therefore, that physical size should have no influence on perceived duration.

Thomas and Cantor (1978) present a more detailed description of the timer. Stimulus onset, after a variable delay, activates the timer, and stimulus offset, after a variable delay, stops the timer. In a SS task, the response is made after a criterion interval, $\mathrm{C}$, or at timer offset, whichever occurs first. If $\mathrm{C}$ occurs first, the response is long; if the timer offset occurs first, the response is short. This view is similar to the onset-offset model proposed by Allan et al. (1971) in that errors are due to onset and offset latencies. It also incorporates Kristofferson's (1977) proposal that duration discrimination can be viewed as temporal order discrimination.

It should be noted that in most conceptions of time perception, the response is dependent upon obtaining a measure of the temporal extent of the stimulus duration. Two exceptions are Kristofferson's (1977) real-time criterion model and the Thomas and Cantor (1978) description of the timer. In both cases, the response is determined by the outcome of a race between the termination of the criterion interval and the internal registration of the termination of the stimulus. The two views differ in the source of errors. For Kristofferson (1977), all of the variability is in the value of the internal criterion; for Thomas and Cantor (1978), all of the variability is in the onset and offset latencies.

Cantor and Thomas (1976), Idson and Massaro (1977), and Massaro and Idson $(1976,1978)$ investigated the relationship between perceived duration and processing time in a different way, by using a SS backward-masking task. On each trial, one of two test stimuli which differ in duration is followed, after a variable interval, by a second stimulus, the mask. In the simplest version of the task, the subject is required to identify the test stimulus as long or short. Performance is influenced by the duration of the interval between the test stimulus and the mask (ISI) and by the duration of the mask. Idson and Massaro (1977) and Massaro and Idson $(1976,1978)$ have shown that increasing ISI increased the correct identification of the long test stimulus, but decreased that of the short test stimulus. Furthermore, correct identification on no-mask relative to mask trials was high for the short stimulus and low for the long stimulus.

Massaro and Idson (1976) proposed a time perception model based on Massaro's (1975) theory for auditory recognition. An auditory stimulus is stored in preperceptual memory, and information in preperceptual store is read out continuously for approximately 250 msec. If a second auditory stimulus, the mask, is presented before processing is completed, the representation of the test stimulus is erased and its processing terminated. Thus the perceived duration of the test stimulus will increase with ISI. If sufficient time is allowed for complete processing of the test stimulus, its perceived duration will be directly related to the test stimulus duration; if less than complete processing time is available, the test stimulus is perceived as shorter than its asymptotic value. At short ISI values, the long stimulus will tend to be inaccurately identified as short, while the short stimulus will be identified accurately. With increasing ISI, a greater proportion of the test stimuli will be identified as long, simultaneously increasing accuracy on the long, and decreasing accuracy on the short, stimuli. It is also assumed that the perceived duration of the mask is incorporated, in an additive manner, into the judgment of the perceived duration of the test stimulus. Since the contribution of the mask is to lengthen the perceived duration of the test stimulus, both test stimuli will tend to be classified as short on no-mask trials, yielding excellent performance on the short test stimulus and poor performance on the long one.

In the original version of the time perception model (Massaro \& Idson, 1976), the rate of growth of perceived duration was assumed to be the same during ISI as during the test stimulus itself. However, the rate was assumed to be dependent upon the duration of the test stimulus, resulting in two rate parameters, $\theta_{S}$ for the short stimulus and $\theta_{L}$ for the long. Allan and Rousseau (1977) and Kristofferson (1977) pointed out that since short and long test stimuli are identical for a major portion of their extent, the rate of growth of the perceived duration has to be identical over this span, and $\theta_{\mathrm{S}}=\theta_{\mathrm{L}}$. Consequently, Idson and Massaro (1977) and Massaro and Idson (1978) modified the original model to include three rate 
parameters: The rate of growth during the test stimulus, $\theta_{\mathrm{D}}$, is independent of the duration of the test stimulus, and the rates of growth during ISI, $\theta_{\mathrm{S}}$ and $\theta_{\mathrm{L}}$, depend upon test stimulus duration.

Idson and Massaro (1977) and Massaro and Idson $(1976,1978)$ have had considerable success in accounting for auditory temporal data. However, the variability among the parameter values estimated from the various studies is surprising considering that the test durations and the mask durations were very similar in all the studies. For example, the estimated value for $\theta_{\mathrm{S}}$ was 102.36 in Massaro and Idson (1976; cited by Massaro \& Idson, 1978), 40.51 in Massaro and Idson (1978), and 25.00 in Idson and Massaro (1977).

The Massaro-Idson model falls into the category of erasure or interruption models for backward masking. Cantor and Thomas (1976) offer an integration model for their backward masking data. They suggest that the mask and the test stimulus are processed as an integrated configuration, whose processing time is dependent upon ISI and on the similarity between the test stimulus and the mask, and influences perceived duration. Cantor and Thomas argue that an integration model and an interruption model make different predictions concerning the relationship between perceived duration and ISI. An interruption model predicts that perceived duration increases monotonically with ISI; an integration model allows perceived duration to be monotonic with ISI, constant, or nonmonotonic, depending upon the similarity between the test stimuli and the mask. Cantor and Thomas found that the perceived duration of one set of stimuli (two different forms) increased with ISI, whereas the perceived duration of another set of stimuli (two different-sized circles) was relatively constant over ISI. They suggest that experiments designed specifically to manipulate similarity might allow a distinction between an integration and an interruption view of visual masking to be made.

Theory is considerably richer now than when Allan and Kristofferson (1974a) summarized the duration discrimination literature only a few years ago. Of the general theories for the perception of brief temporal intervals, the work of Thomas and of Cantor is especially exciting. Assets of their theory are its flexibility, its ability to predict relationships between scaling tasks and duration discrimination tasks, and the emphasis placed on the influence of the type of material and of processing time on perceived duration.

Of the specific models for duration discrimination, the real-time criterion model is the only one that can address the observed invariance in discriminability. The novel feature in this model is that it is the internal criterion interval that is variable rather than the internal value of the stimulus duration. The criterion variance depends upon the range of stimulus duration values being judged. Many features of this model need elaboration, especially the determination of the relationship between criterion variance and stimulus range.

The real-time criterion model specifies that, under some circumstances, order information is sufficient for discrimination among stimuli of varying durations. The response does not depend upon obtaining a measure of the temporal extent of the stimulus duration. It is possible that some of the discrepancies in the literature concerning the relation between stimulus duration and discriminability arise from alternative ways of performing in a time judgment task, specifically on whether the response is based on an order judgment or on the temporal extent of the duration stimulus.

\section{SUMMARY}

There are now a number of fairly well established phenomena to guide theorizing about time perception:

(1) There are considerable data that are consistent with a linear relationship between perceived time and stimulus time. Data that have been interpreted as supportive of a power function as the psychophysical law should be regarded with caution.

(2) Neither discrimination data nor scaling data are in agreement with Weber's law in its simple form. Some of the existing data lend strong support to Getty's generalized form of Weber's law. Other data indicate that the standard deviation of the internal duration distribution is invariant over a considerable range of duration values.

(3) In the absence of feedback, a strong and systematic TOE is usually observed.

(4) Perceived duration is influenced by nontemporal characteristics of the marker. Discrimination performance is also dependent upon the modality and the nature of the marker; however, it is generally unaffected by large variations in the intensive, frequency, and bandwidth characteristics of the marker. The relationship between the effects of nontemporal variables on perceived duration and on discrimination performance has not been studied.

There is no theory for time perception that attempts to encompass all these empirical phenomena. Some models have been concerned primarily with the psychophysical law and/or Weber's law, some primarily with interrelations among different kinds of time-judgment tasks, and some primarily with the role of nontemporal variables and/or processing time on temporal judgments.

\section{REFERENCE NOTES}

1. Ekman, G. Subjective power functions and the method of fractionation. Technical Report No. 34, University of Stockholm, 1956. 
2. Ekman, G., \& Frankenhaeuser, M. Subjective time scales.

Technical Report No. 49, University of Stockholm, 1957.

3. Kaner, C., \& Allan, L. G. Unpublished data. These data are available from L.G.Allan upon request.

4. Kristofferson, A. B. Psychological timing mechanisms. Paper presented at the Fourth Annual Meeting of the Lake Ontario Vision Establishment, Niagara Falls, Ontario, 1973.

5. Hopkins, G. Unpublished data.

6. Hellström, A. On the nature of the time-error. Technical Report Supplement 38, University of Stockholm, 1977.

\section{REFERENCES}

AbeL, S. M. Mechanisms for temporal numerosity in audition. Unpublished doctoral dissertation, McMaster University, 1970.

Abel, S. M. Duration discrimination of noise and tone bursts. Journal of the Acoustical Society of America, 1972, 51, 1219 1223. (a)

ABeL, S. M. Discrimination of temporal gaps. Journal of the Acoustical Society of America, 1972, 52, 519-524. (b)

ADAms, R. D. Intervening stimulus effects on category judgments of duration. Perception \& Psychophysics, 1977, 21, 527-534.

Allan, L. G. Is there a constant minimum perceptual duration? Quarterly Journal of Experimental Psychology, 1976, 28, 71-76.

Allan, L. G. The time-order error in judgments of duration. Canadian Journal of Psychology, 1977, 31, 24-31.

AlLAN, L. G. Comments on current ratio-setting models for time perception. Perception \& Psychophysics, 1978, 24, 444-450.

Allan, L. G., \& Kristofferson, A. B. Psychophysical theories of duration discrimination. Perception \& Psychophysics, 1974, 16, 26-34. (a)

Allan, L. G., \& Kristofferson, A. B. Judgements about the duration of brief stimuli. Perception \& Psychophysics, 1974, 15 , 434-440. (b)

Allan, L. G., Kristofferson, A. B., \& Rice, M. E. Some aspects of perceptual coding of duration in visual duration discrimination. Perception \& Psychophysics, 1974, 15, 83-88.

Allan, L. G., Kristofferson, A. B., \& Wiens, E. W. Duration discrimination of brief light flashes. Perception \& Psychophysics, 1971, 9, 327-334.

Allan, L. G., \& Rousseau, R. Backward masking in judgments of duration. Perception \& Psychophysics, 1977, 21, 482-486.

Anderson, N. H. Note on functional measurement and data analysis. Perception \& Psychophysics, 1977, 21, 201-215.

Avant, L. L., \& Lyman, P. J. Stimulus familiarity modifies perceived duration in prerecognition visual processing. Journal of Experimental Psychology: Human Perception and Performance. 1975, 1, 205-213.

Avant, L. L., Lyman, P. J., \& Antes, J. R. Effects of stimulus familiarity upon judged visual duration. Perception \& Psychophysics, 1975, 17, 253-262.

Behar, I., \& Bevan, W. The perceived duration of auditory and visual intervals: Cross-modal comparison and interaction. American Journal of Psychology, 1961, 74, 17-26.

Berglund, B., Berglund, U., Ekman, G., \& Frankenhaeuser M. The influence of auditory stimulus intensity on apparent duration. Scandinavian Journal of Psychology, 1969, 10, 21-26.

Bindra, D., \& Waksberg, H. Methods and terminology in studies of time estimation. Psychological Bulletin, 1956, 53, 155-159.

Björkman, M., \& Holmkvist, $\mathrm{O}$. The time-order error in the construction of a subjective time scale. Scandinavian Journal of Psychology, 1960, 1, 7-13.

BLAKELY, W. A. The discrimination of short empty temporal intervals. Unpublished doctoral dissertation, University of Illinois, 1933.

Blankenship, D. A., \& Anderson, N. H. Subjective duration: A functional measurement analysis. Perception \& Psychophysics, 1976, 20, 168-172.

Boвko, D.J., Thompson, J. G. \& Schiffman, H. R. The perception of brief temporal intervals: Power functions for auditory and visual stimulus intervals. Perception, 1977, 6, 703709.

Bralda, L. D., \& Durlach, N. I. Intensity perception II. Resolution in one-interval paradigms. Journal of the Acoustical Society of America, 1972, 51, 483-502.

Brown, D. R., \& Hiтchсоск, L. Time estimation: Dependence and independence of modality-specific effects. Perceptual and Motor Skills, 1965, 21, 727-734.

Buffardi, L. Factors affecting the filled-duration illusion in the auditory, tactual, and visual modalities. Perception \& Psychophysics, 1971, 10, 292-294.

Cantor, N. E., \& Thomas, E. A. C. Visual masking effects on duration, size, and form discrimination. Perception \& Psychophysics, 1976, 19, 321-327.

Cantor, N. E., \& Thomas, E. A. C. Control of attention in the processing of temporal and spatial information in complex visual patterns. Journal of Experimental Psychology: Human Perception and Performance, 1977, 3, 243-250.

Carbotte, R. M. Retention of time information in forced-choice duration discrimination. Perception \& Psychophysics, 1973, 14, 440-444.

Carbotte, R. M., \& Kristofferson, A. B. On energy dependent cues in duration discrimination. Perception \& Psychophysics, $1973,14,501-505$.

Carlson, V. R., \& Feinberg, I. Consistency among methods of time judgment for independent groups. Proceedings of the American Psychological Association, 1968, 3, 83-84. (a)

Carlson, V. R., \& Feinberg, I. Individual variations in time judgment and the concept of an internal clock. Journal of Experimental Psychology, 1968, 77, 631-640. (b)

Carlson, V. R., \& Feinberg, I. Time judgment as a function of method, practice, and sex. Journal of Experimental Psychology, 1970, 85, 171-180.

Clausen, J. An evaluation of experimental methods of time judgment. Journal of Experimental Psychology, 1950, 40, 756761.

Craig, J. C. A constant error in the perception of brief temporal intervals. Perception \& Psychophysics, 1973, 13, 99-104.

Creelman, C. D. Human discrimination of auditory duration. Journal of the Acoustical Society of America, 1962, 34, 582-593.

Curtis, D. W. Magnitude estimations and category judgments of brightness and brightness intervals: A two-stage interpretation. Journal of Experimental Psychology, 1970, 83, 201-208.

Curtis, D. W., Attrneave, F., \& Harrington, T. L. A test of a two-stage model of magnitude judgment. Perception \& Psychophysics, 1968, 3, 25-31.

Curtis, D. W., \& Rule, S. J. Judgment of duration relations: Simultaneous and sequential presentation. Perception \& Psychophysics, 1977, 22, 578-584.

Danziger, K., \& Du Preez, P. D. Reliability of time estimation by the method of reproduction. Perceptual and Motor Skills, 1963, 16, 879-884.

DeVANE, J. R. Word characteristics and judged duration for two response sequences. Perceptual and Motor Skills, 1974, 38, 525-526.

Divenyi, P. L., \& Danner, W. F. Discrimination of time intervals marked by brief acoustic pulses of various intensities and spectra. Perception \& Psychophysics, 1977, 21, 125-142.

Doenring, D. G. Accuracy and consistency of time-estimation by four methods of reproduction. American Journal of Psychology, 1961, 74, 27-35.

Dooв, L. S. Patterning of time. New Haven: Yale University Press, 1971.

Du Preez, P. D. Relation between verbal estimation and reproduction of a short time interval: Preliminary study. Perceptual and Motor Skills, 1963, 17, 45-46.

Durlach, N. I., \& Braida, L. D. Intensity perception. I. Preliminary theory of intensity resolution. Journal of the Acoustical Society of America, 1969, 46, 372-383.

Efron, R. Effect of stimulus duration on perceptual onset and offset latencies. Percetpion \& Psychophysics, 1970, 8, 231-234. 
ErRon, R. An invarient characteristic of perceptual systems in the time domain. In S. Kornblum (Ed.), Attention and performance IV. New York: Academic Press, 1973.

EiJkman, E., \& Vendrik, A. J. H. Can a sensory system be specified by its internal noise? Journal of the Acoustical Society of America, 1965, 37, 1102-1109.

Eisler, H. Subjective duration and psychophysics. Psychological Review, 1975, 82, 429-450.

Eister, H. Experiments on subjective duration 1868-1975: A collection of power function exponents. Psychological Bulletin, 1976, 83, 1154-1171.

EкMAN, G. Is the power law a special case of Fechner's law? Perceptual and Motor Skills, 1964, 19, 730.

Fraisse, P. The psychology of time. New York: Harper \& Row, 1963.

Frankenhaeuser, M. Subjective time as affected by gravitational stress. Scandinavian Journal of Psychology, 1960, 1, $1-6$.

GETTY, D. J. Discrimination of short temporal intervals: A comparison of two models. Perception \& Psychophysics, 1975, $18,1-8$.

Getry, D. J. Counting processes in human timing. Perception \& Psychophysics, 1976, 20, 191-197.

Giввon, J. Scalar expectancy theory and Weber's Law in animal timing. Psychological Review, 1977, 84, 279-325.

Gilliland, A. R., \& Humphreys, D. W. Age, sex, method, and interval as variables in time estimation. Journal of Genetic Psychology, 1943, 63, 123-130.

Gilliland, A. R., \& Martin, R. Some factors in estimating short time intervals: Journal of Experimental Psychology, 1940, 27, 243-255.

Goldfarb, J. L., \& Goldstone, S. Time judgment: A comparison of filled and unfilled durations. Perceptual and Motor Skills, 1963, 16, 376. (a)

Goldfarb, J. L., \& Goldstone, S. Proprioceptive involvement, psychophysical method and temporal judgment. Perceptual and Motor Skills, 1963, 17, 286. (b)

Goldfarb, J. L., \& Goldstone, S. Properties of sound and the auditory-visual difference in time judgment. Perceptual and Motor Skills, 1964, 19, 606.

Goldstone, S. Production and reproduction of duration: Intersensory comparisons. Perceptual and Motor Skills, 1968, 26, $755-760$.

Goldstone, S., Boardman, W. K., \& Lhamon, W. T. Intersensory comparisons of temporal judgments. Journal of Experimental Psychology, 1959, 57, 243-248.

Goldstone, S., \& Goldfarb, J. L. Judgment of filled and unfilled durations: Intersensory factors. Perceptual and Motor Skills, 1963, 17, 763-774.

Goldstone, S., \& Goldfarb, J. L. Auditory and visual time judgment. Journal of General Psychology, 1964, 70, 369-387. (a)

Goldstone, S., \& GoldfarB, J. L. Direct comparison of auditory and visual durations. Journal of Experimental Psychology, $1964,67,483-485$. (b)

Goldstone, S., Jernigan, C., Lhamon, W. T., \& Boardman. W. K. A further note on intersensory differences in temporal judgments. Perceptual and Motor Skills, 1959, 9, 252.

Goldstone, S., \& Lhamon, W. T. Studies of the auditory-visual differences in human time judgments: 1. Sounds are judged longer than lights. Perceptual and Motor Skills, 1974, 39, 63-82.

Golnstone, S., Lhamon, W. T., \& Sechzer, J. Light intensity and judged duration. Bulletin of the Psychonomic Society, 1978, 12, 83-84.

Gomez, L. M., \& Robertson, L. C. The filled-duration illusion: The function of temporal and nontemporal set. Perception \& Psychophysics, 1979, 25, 432-438.

GoodfezLow, L. D. An empirical comparison of audition, vision, and touch in the discrimination of short intervals of time. American Journal of Psychology, 1934, 46, 243-258.

Green, D. M., \& LuCE, R. D. Variability of magnitude estimates: A timing theory analysis. Perception \& Psychophysics, 1974, 15, 291-300.
Green, D. M., Luce, R. D., \& Duncan, J. E. Variability and sequential effects in magnitude production and estimation of auditory intensity. Perception \& Psychophysics, 1977, 22, 450-456.

Hawkes, G. R., Bailey, R. W., \& Warm, J. S. Method and modality in judgments of brief stimulus duration. Journal of Auditory Research, 1961, 1, 133-144.

Hélström, A. Time-errors are perceptual. Psychological Research, 1977, 39, 345-388.

HENRY, F. M. Discrimination of the duration of a sound. Journal of Experimental Psychology, 1948, 38, 734-743.

Hornstein, A. D., \& Rotter, G. S. Research methodology in temporal perception. Journal of Experimental Psychology, 1969, 79, 561-564.

Idson, W. L., \& Massaro, D. W. Perceptual processing and experience of auditory duration. Sensory Processes, 1977, 1, 316-337.

IspaELI, N. Illusions in the perception of short time intervals. Archives of Psychology, 1930, 18, No. 113.

JAMIESON, D. G. Two presentation order effects. Canadian Journal of Psychology, 1977, 31, 184-194.

Jamieson, D. G., \& Petrusic, W. M. Presentation order effects in duration discrimination. Perception \& Psychophysics, $1975,17,197-202$. (a)

Jamifison, D. G., \& Petrusic, W. M. The dependence of timeorder error direction on stimulus range. Canadian Journal of Psychology, 1975, 29, 175-182. (b)

Jamieson, D. G., \& Petrusic, W. M. Pairing effects and timeorder errors in duration discrimination. Perception \& Psychophysics, 1975, 18, 107-113. (c)

Jamieson, D. G., \& Petrusic, W. M. On a bias induced by the provision of feedback in psychophysical experiments. Acta Psychologica, 1976, 40, 199-206.

Jamieson, D. G., \& Petrusic, W. M. Feedback versus an illusion in time. Perception, 1978, 7, 91-96.

Jesteadt, W., Luce, R. D., \& Green, D. M. Sequential effects in judgments of loudness. Journal of Experimental Psychology: Human Perception and Performance, 1977, 3, 92-104.

Jones, A., \& Maclean, M. Perceived duration as a function of auditory stimulus frequency. Journal of Experimental Psychology, 1966, 71, 358-364.

Kinchla, J. Duration discrimination of acoustically defined intervals in the 1 - to 8 -sec range. Perception \& Psychophysics, 1972, 12, 318-320.

KristofFERSON, A. B. Low-variance stimulus-response latencies: Deterministic internal delays? Perception \& Psychophysics, 1976, 20, 89-100.

Kristofferson, A. B. A real-time criterion theory of duration discrimination. Perception \& Psychophysics, 1977, 21, 105-117.

Kristofferson, A. B., \& Allan, L. G. Successiveness and duration discrimination. In S. Kornblum (Ed.), Attention and performance. IV. New York: Academic Press, 1973.

KruUP, K. Influence of method on time judgments. Australian Journal of Psychology, 1961, 13, 44-53.

Künnapas, T., Hallsten, L., \& Söderberg, G. Interindividual differences in homomodal and heteromodal scaling. Acta Psychologica, 1973, 37, 31-42.

Loeb, M., Behar, I., \& Warm, J. S. Cross-modal correlations of the perceived durations of auditory and visual stimuli. Psychonomic Science, 1966, 6, 87.

Luce, R. D., \& Galanter, E. Discrimination. In R. D. Luce, R. R. Bush, \& E. Galanter (Eds.), Handbook of mathematical psychology (Vol. 1). New York: Wiley, 1963.

Luck, R. D., \& Green, D. M. The response ratio hypothesis for magnitude estimation. Journal of Mathematical Psychology, 1974, 11, 1-14.

Massaro, D. W. Experimental psychology and information processing. Chicago: Rand-McNally, 1975.

Massaro, D. W., \& Idson, W. L. Temporal course of perceived auditory duration. Perception \& Psychophysics, 1976, 20, 331-352. 
Massaro, D. W., \& Idson, W. L. Target-mask similarity in backward recognition masking of perceived tone duration. Perception \& Psychophysics, 1978, 24, 225-236.

McConchie, R. D., \& Rutschmann, J. Reliability of time estimation: Effect of a preceding reproduction series on the reliability of subsequent verbal estimates of the same standard stimuli. Perceptual and Motor Skills, 1970, 31, 51-55.

McConchie, R. D., \& RutschmanN, J. Human time estimation: On differences between methods. Perceptual and Motor Skills, 1971, 32, 319-336.

Michon, J. A. Magnitude scaling of short durations with closely spaced stimuli. Psychonomic Science, 1967, 9, 359-360.

Michon, J. A, processing of temporal information and the cognitive theory of time experience. In J. T. Fraser, F. C Haber, \& J. A. Muller (Eds.), The study of time. Heidelberg, Germany: Springer, 1972.

MichoN, J. A. The making of the present. In J. Requin (Ed.) Attention and performance VII. Hillsdale, N.J: Erlbaum, 1978.

NiLsson, T. H. Two-pulse-interval vision thresholds. Journal of the Optical Society of America, 1969, 59, 753-756.

Nilsson, T. H. Visual temporal discriminations of brief pulse intervals. Vision Research, 1979, 19, 41-48.

Ochberg, F. M., Pollack, I. W., \& Meyer, E. Reproduction and estimation methods of time judgment. Perceptual and Motor Skills, 1965, 20, 653-656.

Ornstein, R. E. On the experience of time. Baltimore: Penguin Books, 1969.

Painton, S. W., Cullinan, W. L., \& Mencke, E. O. Individual pitch functions and pitch-duration cross-dimensional matching. Perception \& Psychophysics, 1977, 21, 469-476.

Penner, M. J. The perception of offset: A problem of decision criteria. Perception \& Psychophysics, 1975, 17, 587-590.

Penner, M. J. The effect of marker variability on the discrimination of temporal intervals. Perception \& Psychophysics, 1976, 19, 466-469.

Penner, M. J. Variability in offset judgments. Bulletin of the Psychonomic Society, 1978, 12, 32-34.

Philip, B. R. The effect of interpolated and extrapolated stimuli on the time order error in the comparison of temporal intervals. Journal of General Psychology, 1947, 36, 173-187.

Pöppel, E. Time perception. In R. Held, W. Leibowitz, \& H. L. Teuber (Eds.), Handbook of sensory physiology (VIII): Perception. Heidelberg, Germany: Springer, 1978.

Rousseau, R., \& Kristofferson, A. B. The discrimination of bimodal temporal gaps. Bulletin of the Psychonomic Society, 1973, 1, 115-116.

Rule, S. J., Curtis, D. W., \& Markley, R. P. Input and output transformations from magnitude estimation. Journal of Experimental Psychology, 1970, 86, 343-349.

Schiffman, H. R., \& BoвKo, D. J. Effects of stimulus complexity on the perception of brief temporal intervals. Journal of Experimental Psychology, 1974, 103, 156-159.

Schiffman, H. R., \& Boвко, D. J. The role of number and familiarity of stimuli in the perception of brief temporal intervals. American Journal of Psychology, 1977, 90, 85-93.

SiEgman, A. W. Intercorrelation of some measures of time estimation. Perceptual and Motor Skills, 1962, 14, 381-382.

Small, A. M., Jr., \& Campeell, R. A. Temporal differential sensitivity for auditory stimuli. American Journal of Psychology $1962,75,401-410$.

Spivak, G., \& Levine, M. Consistency of individual differences in time judgments. Perceptual and Motor Skills, 1964, 19, 83-92.

STEINER, S. Apparent duration of auditory stimuli. Journal of Auditory Research, 1968, 8, 195-205.

Stevens, S. S., \& Galanter, E. H. Ratio scales and category scales for a dozen perceptual continua. Journal of Experimental Psychology, 1957, 54, 377-411.

Stevens, S. S., \& Greenbaum, H. B. Regression effect in psychophysical judgment. Perception \& Psychophysics, 1966, 1. 439-446.

Stoтt, L. H. The discrimination of short tonal durations. Unpublished doctoral dissertation, University of Illinois, 1933.
Stotr, L. H. Time-order errors in the discrimination of short tonal durations. Journal of Experimental Psychology, 1935, 18, 741-766.

Tanner, T. A., JR., Patton, R. M., \& Atrinson, R. C. Intermodality judgments of signal duration. Psychonomic Science, 1965, 2, 271-272.

Thomas, E. A. C., \& Brown, I., Jr. Time perception and the filled-duration illusion. Perception \& Psychophysics, 1974, 16, 449-458.

Thomas, E. A. C., \& Cantor, N. E. On the duality of simultaneous time and size perception. Perception \& Psychophysics, $1975,18,44-48$.

Thomas, E. A. C., \& Cantor, N. E. Simultaneous time and size perception. Perception \& Psychophysics, 1976, 19, 353-360.

Thomas, E. A. C., \& Cantor, N. E. Interdependence between the processing of temporal and non-temporal information. In J. Requin (Ed.), Attention \& performance VII. Hillsdale, N.J: Erlbaum, 1978.

Thomas, E. A. C., \& Weaver, W. B. Cognitive processing and time perception. Perception \& Psychophysics, 1975, 17, 363-367.

Thompson, J. G., Shiffman, H. R., \& Boвko, D. J. The discrimination of brief temporal intervals. Acta Psychologica, $1976,40,489-493$.

Treisman, M. Temporal discrimination and the indifference interval: Implications for a model of the "internal clock." Psychological Monographs, 1963, 77, 13, Whole No. 576).

Warm, J. S., Greenberg, L. F., \& Dube, C. S., Iİ. Stimulus and motivational determinants in temporal perception. Journal of Psychology, 1964, 58, 243-248.

WARM, J. S., \& MCCRAY, R. E. Influence of word frequency and length on the apparent duration of tachistoscopic presentations. Journal of Experimental Psychology, 1969, 79, 56-58.

W ARM, J. S., Stutz, R. M., \& VAssolo, P. A. Intermodal transfer in temporal discrimination. Perception \& Psychophysics, 1975, 18, 281-286.

Woodrow, H. Behavior with respect to short temporal stimulus forms. Journal of Experimental Psychology, 1928, 11, 167198.

Woodrow, H. The reproduction of temporal intervals. Journal of Experimental psychology, 1930, 13, 473-499.

Woonrow, H. Individual differences in the reproduction of temporal intervals. American Journal of Psychology, 1933, 45, 271-281.

WoODRow, H. The temporal indifference interval determined by the method of mean error. Journal of Experimental Psychology, $1934,17,167-188$.

Woodrow, $\mathrm{H}$. The effect of practice upon time-order errors in the comparison of temporal intervals. Psychological Review, $1935,42,127-152$.

Woodrow, H. Time perception. In S. S. Stevens (Ed.), Handbook of experimental psychology. New York: Wiley, 1951.

Woodrow, H., \& StotT, L. H. The effect of practice on positive time-order errors. Journal of Experimental Psychology, 1936, 19, 694-705.

ZELKIND, I. Factors in time estimation and a case for the internal clock. Journal of General Psychology, 1973, 88, 295-301.

Zelikind, I., \& Sprug, J. Time research: 1172 studies. Metuchen, N.J: Scarecrow Press, 1974.

\section{NOTE}

1. Creelman's (1962) Equation 1 for $d^{\prime}$ for a FC task is incorrect, and the correct equation is given in Allan and Kristofferson (1974a). Divenyi and Danner (1977) present the erroneous form in their Equation 1, and their modified model presented in Equation 6 is derived from Equation 1. If their parameter estimates are based on Equation 6, they will be in error.

(Received for publication April 23, 1979 revision accepted September 17, 1979.) 